\title{
A OCORRÊNCIA HOMONÍMICA COMO FENÔMENO QUE INTERFERE NO PROCESSO DE CRIAÇÃO EM MANUSCRITOS ESCOLARES
}

\section{THE HOMONYMIC OCCURRENCE AS PHENOMENON THAT INTERFERE IN THE PROCESS OF CREATING IN THE SCHOOL MANUSCRIPT}

\author{
Maria Hozanete Alves de Lima* \\ Eduardo Calil ${ }^{\dagger}$
}

RESUMO: Este trabalho discute a ocorrência homonímica como um dos fenômenos que pode interferir em processos de criação de narrativas ficcionais em ambiente escolar. Analisamos o diálogo e o manuscrito escolar estabelecido por uma dupla de alunas recém alfabetizadas. A partir do campo teórico delineado pela Genética Textual, indicamos como este fenômeno pode ser reconhecido pelas escreventes novatas e, a partir de suas "escutas", colocá-las em posição de scriptor.

PALAVRAS-CHAVE: Escola. Produção textual. Criatividade. Escreventes novatos. Autoria.

\begin{abstract}
This paper discusses the homonymic occurrence as one of the phenomena that can interfere in the fictional narratives' creation processes in a school environment. We analyzed the dialogue and the school manuscript provided by a pair of newly literate students. From the theoretical framework outlined by Textual Genetics, we point out the way in which this phenomenon can be recognized by the writers and, through their "hearings", put them in scriptor's position.

KEYWORDS: School. Textual production. Creativity. Novice writer. Authorship.
\end{abstract}

* Universidade Federal do Rio Grande do Norte (UFRN), Natal, Estado do Rio Grande do Norte, Brasil. Doutora em Linguística e professora (categoria funcional Adjunto IV) do Departamento de Letras, vinculada ao Programa de Pós-Graduação em Estudos da Linguagem. E-mail : hozalima@ufrnet.br.

${ }^{\dagger}$ Universidade Federal de Alagoas (UFAL), Maceió, Estado de Alagoas, Brasil. Professor do Programa de Pós-graduação em Letras e Linguística e do Programa de Pós-graduação em Educação, bem como pesquisador vinculado ao $\mathrm{CNPq}$ (processo 305312/2011-1).E-mail: eduardocalil@hotmail.com. 


\section{A OCORRÊNCIA HOMONÍMICA COMO FENÔMENO QUE INTERFERE NO PROCESSO DE CRIAÇÃO EM MANUSCRITOS ESCOLARES}

\section{INTRODUÇÃO}

Inserido nos estudos sobre autoria e criação textual de alunos recémalfabetizados, vinculamos nosso estudo ao Laboratório do Manuscrito Escolar (LAME), cujo objeto de investigação busca desvendar algumas relações entre sujeito, língua e sentido estabelecidas a partir da escrita de histórias inventadas, de poemas ou de reescritas de textos de diferentes gêneros textuais. A referência aos estudos da Genética Textual (Grésillon, 1994; Biasi, 2011), dedicados a analisar os caminhos da criação literária, através dos dossiês genéticos (rascunhos, anotações, cartas, manuscritos...) de escritores consagrados, é fundamental para nosso campo de investigação. Neste sentido, consideramos que a atividade textual em devir, que resulta na emergência da produção final, traz

\footnotetext{
os traços de um ato, uma enunciação em marcha, uma criação se fazendo, com seus avanços e seus bloqueios, seus acréscimos e seus riscos, suas pulsões desenfreadas e suas reparações, seus relances e suas hesitações, seus excessos e suas faltas, seus gastos e suas perdas (GRÉSILLON, 1994, p.33).
}

Como tem sido destacado desde os trabalhos de Fabre (1990, 1992, 2013) ao analisar as rasuras presentes em brouillon de alunos de 6 a 8 anos, estes "traços de uma ato, de uma enunciação em marcha" também se manifestam na escritura escolar, apesar de suas limitações linguísticas e cognitivas e suas especificidades didáticas. Por essas razões, o "manuscrito escolar" visa a valorizar não somente sua importância cultural e histórica, mas também dar a ele um estatuto científico. O "manuscrito escolar" seria 
de fundo", como referência, enquanto cenário que contextualiza e situa o ato de escrever (CALIL, 2008, p.25)

Entretanto, o manuscrito, ainda que possa ter um caráter inacabado, incompleto, fragmentado, é um objeto que preserva, apenas graficamente, o resultado do traço na superfície escrita. Invisíveis no manuscrito final, o que foi pensado pelo escrevente no momento da efetivação de uma rasura resta perdido.

Usando como estratégia didática propostas de escritura colaborativa, quando dois alunos tem a tarefa de escreverem um único texto, pudemos ter acesso ao que dizem antes, durante e após o ato de escrever. Cena exemplar na investigação de questões significativas à estrutura, à língua e ao discurso, o diálogo entre os alunos pode colocar em destaque suas posições subjetivas, o modo como estão pensando sobre o que estão escrevendo e como reagem à palavra dita. Há, nesse tipo de produção, visibilidade para os retornos das palavras sobre elas mesmas e sobre o dizer (AUTHIER-REVUZ, 1998), para as trocas verbais, para a negociação entre o que pode ou não entrar no texto, para os apagamentos e supressões ocorridas ao longo do processo de criação.

Embora a escrita de textos por díades de alunos possa ser uma atividade pouco presente no ambiente escolar, seu registro fílmico oferece significativos elementos para se observar e interpretar como os próprios alunos dialogam e interagem entre si e com o próprio texto em curso. Este material possibilita ao linguista reconhecimento, no tempo real da fala espontânea, de aspectos metalinguísticos e metaenunciativos responsáveis pela produção de sentidos e de unidade textual. As operações de retorno sobre a língua e sobre o texto permitem dar visibilidade às relações de alteridade e a seus efeitos sobre os percursos que alimentam a produção final de um manuscrito.

A reflexão proposta neste artigo elege a homonímia enquanto um dos fenômenos que pode interferir na incidência de elementos imprevisíveis que, ao serem enunciados, alteram ou dirigem os caminhos da escritura criativa. A análise sobre a produção textual aqui desenvolvida é um aprofundamento e uma contribuição às leituras apresentadas em Calil (2004) e Felipeto (2008). Teoricamente, recorremos à categoria de equívoco, como pensada por Milner (1987), para amparar nossas investigações.

\section{A COLETA DOS MANUSCRITOS}

O processo de escritura a dois a ser analisado foi coletado em 1992 e faz parte do conjunto de processos de escritura em ato em que Isabel e Nara, duas alunas recém alfabetizadas, com 6 anos de idade, escrevem histórias inventadas. A metodologia empregada para a coleta deste material foi orientada por dois princípios básicos:

1. Preservar as características contextuais das produções desenvolvidas pelos alunos na sala de aula;

2. Interferir minimamente nas práticas pedagógicas adotadas pelo professor.

A filmagem da apresentação da proposta pela professora e, em seguida, da díade trabalhando colaborativamente, garantiu o registro do contexto simbólico que envolvia a escritura dos textos. Além disso, este procedimento metodológico favoreceu, como dissemos, o acesso aos diálogos e decisões tomadas pelos escreventes para a escolha do que seria ou poderia ser escrito em sua história. As várias semioses capturadas pela filmadora (gestos, risos, olhares, falas, rasuras, ambiente da sala de aula, etc.) deu a este material seu caráter multimodal. O processo de escritura que gerou o manuscrito "A família F atrapalhada" será o objeto de nossa análise. O dialogo 
estabelecido por estas alunas ao longo deste processo está marcado pelas "ocorrências homonímicas", potencializadoras de efeitos de criação.

\title{
2 OS MOVIMENTOS DE CRIAÇÃO NOS MANUSCRITOS ESCOLARES
}

Discutir sobre o processo de criação ou até mesmo sobre o termo "criação" não é uma questão que se esgota neste trabalho e, quiçá, em qualquer outro estudo, dada a abrangência e a relação deste termo em múltiplos campos de saber. Consideremos como nosso ponto de partida o título Bastidores da criação literária. Nesta obra, Philippe Willemart (1999) coloca em cena as origens culturais do conceito de criação relacionando-o com a escritura literária. Para o autor, nessa atividade,

\begin{abstract}
As palavras e as letras adquirem uma autonomia até então desconhecida, o escritor se torna scriptor, isto é, se coloca a serviço da língua e de suas rimas. O escritor não procura mais encontrar o que está lá ou o que ocorreu lá, mas elabora novas formas. O presente não é mais um passado mascarado ou sua repetição, talvez uma presença recuperando um passado, mas alargando-o às dimensões do contemporâneo e do futuro (WILLEMART, 1999, p.91)
\end{abstract}

Grosso modo, a "criação" pode ser lida, através dessas palavras, como a parte visível e concreta de movimentos "autônomos desconhecidos", sem que um "autor" ou "criador" esteja em seu controle. Nisto, o autor se torna scriptor, e se coloca a serviço da língua, das palavras, das letras, das rimas, que "adquirem uma autonomia até então desconhecida". Para nós, o scriptor, como Willemart enfatiza, está preso ao funcionamento linguístico-discursivo, elaborando novas formas e alargando as possibilidades de uso dos signos linguísticos.

Conferindo o diálogo eleito, poderemos pensar de modo mais objetivo sobre o movimento de "criação" e sobre as marcas do escrevente na produção de histórias inventadas.

\section{Diálogo 1}

1. ISABEL: - Bom... é... história inventada ou história... aii... que que a gente...

2. NARA: - ...escreve ...

3. ISABEL: - (dizendo como quem está lembrando que se deve escrever o título da história) Título!

4. NARA: - Título eu sei que a gente vamos escrever!

5. ISABEL: - ... éé... título a gente escreve depois...

6. NARA: - E fim!... Fim...

7. ISABEL : - (com voz muito baixa) fim... a gente escreve... um menino chamado fim... a mãe chamava...

8. NARA: - (falando alto) Espera... você me deu uma boa ideia.

9. ISABEL: - Calma! Era...

10. NARA: - Era um menino chamava fim...

11. ISABEL: - E a mãe chamava fima e o pai chamava fimo (rindo)

12. NARA: - Ah! Não, fumo o pai chamava... e a mãe chamava fina... (rindo)

13. ISABEL: - Fina... e o fim chamava... e o... e o filho chamava fim.

14. NARA: - Fim. 
O texto dialogal é construído sob a força da emergência de elementos imprevisíveis, orientando novas possibilidades de significância e de relações entre as palavras. Na decisão do que vai ser escrito, a antecipação de uma dúvida, registrada com o uso do conector alternativo "ou": "Bom... é... história inventada ou história... aii... que que a gente...".

Isabel diz "Título" (linha 3), eis o que se pode escrever na história. Não a palavra "título", mas um conjunto de caracteres linguísticos que seja reconhecido como o título da história, característica fortemente recorrente em narrativas ficcionais (contos, fábulas etc.). Complementarmente, Nara responde "E fim" (linha 6), outra palavra da ordem do que se repete, sinalizando que a história a ser contada, lida ou escrita acabou, foi finalizada.

Escrever o "título" da história e marcar a finalização com a palavra "Fim" refletem saberes históricos, cujos traços são recuperados, por exemplo, pelo enunciado "Título eu sei que a gente vamos escrever" (linha 4). As falas iniciais, na produção do texto "A família F atrapalhada", alicerçam os primeiros passos dessa escritura em ato e simbolizam a presença de saberes e a repetição de discursos historicamente marcados.

As falas subsequentes (linhas 7 - 14) liberam, ao lado de semioses diferentes a voz baixa, o falar alto, a agitação -, a descoberta, a emergência de novas possibilidades nos usos das palavras, instaurando uma textualidade imprevisível. Nara e Isabel atropelam suas falas no início, suprimindo palavras recorrentes na frase inicial que vai compor a história inventada:

ISABEL: - Calma! Era...

NARA: - Era uma um menino que se chamava fim...

A expressão "era uma vez um menino que se chamava" é amalgamada pela urgência e pela emergência do ato de nomear o personagem do texto. $\mathrm{O}$ nome próprio não vem do nada, sua "criação" é enlaçada de dois modos. De um lado, trazendo consigo os lugares e as posições históricas que significam a forma fim como uma marca linguística indiciadora de "término"; de outro, ganhando estatuto de nome próprio, a partir das relações com outras formas, a saber: "um menino chamava...". O fato de as meninas rirem e falarem alto simbolizam o "reconhecimento" desse nó e o desenlace ao qual o termo "fim" estaria preso.

Nesse instante, já podemos indagar: "Fim" é uma palavra homonímica? Seria ela uma única forma significante com significados ou valores distintos? Deixamos de lado as discussões sobre o fenômeno da homonímia em sua relação com a polissemia, por entendermos que a polissemia, grosso modo, diz respeito a uma única forma significante com significados que participam do mesmo campo semântico, o que não seria o caso da homonímia.

É frutífero para nossas análises, retomar as investigações do linguista Ferdinand Saussure (1999) sobre a teoria do valor e do signo, presente no Curso de Linguística Geral (CLG). O signo linguístico, em Saussure, é um todo formado por dualidades: o significado e o significante. Deste modo, podemos considerar, inicialmente, o significante "fim" como uma marca linguística cujo sentido é representar um "ponto final; término" (HOUAISS, 2001). Essa relação sígnica, "Fim/"ponto final; término", sofre fissuras quando a palavra estabelece outra relação, "Fim/nome próprio". Essa nova relação interna, porém, é assegurada por meio das relações externas que o significante "Fim" passa a manter com outros significantes na cadeia linguística em que se encontra. 
Ferdinand Saussure antecipou, no Curso de Linguística Geral, como essa possibilidade de mudança no interior do signo linguístico poderia se realizar. O sentido seria estabelecido através de relações, de posições que um signo, por ventura, venha ocupar na cadeia linguística: "visto ser a língua um sistema em que todos os termos são solidários e o valor de um resulta tão-somente da presença simultânea de outros" (SAUSSURE, 1999, p.149). Essas relações na história "A família F atrapalhada" podem ser consideradas a partir do seguinte quadro:

$\begin{array}{ll}\begin{array}{l}\text { Era uma vez um menino } \\ \text { chamado }\end{array} & \text { João } \\ \text { Era uma vez um pai chamado } & \text { José } \\ \text { Era uma vez uma mãe chamada } & \text { Maria } \\ \text { Era uma vez uma mãe chamada } & \text { Júlia } \\ \text { Era uma vez um pai chamado } & \text { Fernando } \\ \begin{array}{l}\text { Era uma vez um menino } \\ \text { chamado }\end{array} & \text { Fim }\end{array}$

A possibilidade de "fim" ocupar o posto de outro signo como "Maria" ou João" faz dele uma "ocorrência homonímica" que, na produção do texto, mobilizará relações imprevisíveis. O agrupamento indicia que na cadeia "o todo vale pelas partes e as partes valem pelo todo". Nesse sentido, ao enunciar certas relações sígnicas, a exemplo de "era uma vez um menino chamado Fim", um nome próprio se ergue através da relação que mantém com os demais signos.

A relação horizontal, de signo a signo, Saussure chamou de relação sintagmática; e a vertical, por sua vez, de paradigmática. "Fim", desse modo, entra, paradigmaticamente, no lugar de "João", "José", Maria", "Júlia" e "Fernando", assumindo o estatuto de nome próprio. Todavia, é necessário considerar que não perde o significado anterior; agora, ativa continuamente os dois sentidos, promovendo, na extensão do texto, ocorrências homonímicas.

Assumimos que a história é marcada por "ocorrências homonímicas" e não propriamente por formas homonímicas. A homonímia seria, para a linguística, um fenômeno que vai permitir a cristalização de significados diferentes para a mesma forma significante; já a "ocorrência homonímica" é de outra ordem, efêmera, rápida, imprevisível, chistosa e dependente de um sujeito que, da posição que ocupa, permite a manifestação na língua de outra dimensão que não seja o espaço do repetível; por assim dizer, a "dimensão do equívoco" (MILNER, 1987).

\section{HOMONÍMIA X OCORRÊNCIA HOMONÍMICA}

$\mathrm{Na}$ Literatura, uma única forma, quando apresenta valores ou significados distintos, é tomada como uma homonímia. O fenômeno da homonímia, grosso modo, é compreendido como a propriedade de duas ou mais formas linguísticas, inteiramente distintas quanto às significações, apresentarem semelhança no plano gráfico ou no plano fônico. Originária do grego Homonymos - homo (igual, semelhante) + ónoma (nome para designar pessoas ou coisas) -, a palavra homonímia chega às línguas românicas pelo latim homonymia, significando propriedade do que é homônimo.

A Nomenclatura Gramatical Brasileira reconhece três tipos de homônimos: 
$>$ Homófonos - do grego homophônos - homos + phônê (som) - palavras que apresentam significantes gráficos diferentes, significantes sonoros idênticos e sentidos diferentes, a exemplo de sessão (reunião), seção (repartição) e cessão (ato de ceder);

$>$ Homógrafos - do grego homo + grafo - palavras que possuem significantes gráficos idênticos, pronúncia e sentido diferentes: seco (do verbo "secar") e seco (adjetivo “enxuto");

$>$ Homógrafos e Homófonos ou Homônimos Perfeitos (do lat. perfectu - per prefixo indicador de totalidade, intensidade) + facere (fazer); daí, feito completamente, feito até o fim) - palavras que apresentam identidade tanto no plano gráfico quanto no sonoro, todavia, de sentidos diferentes: são (verbo ser), são (sadio), São (santo).

Essa nomenclatura, aparentemente clara, não se mantém harmônica entre os linguistas. As diferenças conceituais denunciam o ponto de vista que os autores assumem na condução da terminologia. Vejamos alguns exemplos.

Mattoso Câmara Júnior (1964) privilegia a materialidade fônica, de modo que considera homografia um conceito artificial. Dubois et al. (1993) ressaltam o fato de os homônimos apresentarem grafias diferentes e defendem o termo heterógrafo no lugar de homofonia. Zélio dos Santos Jota (1981) e John Lyons (1987) preferem chamar as formas destacadas por Mattoso de homônimos parciais, e quando a homonímia se realiza através de um único meio, fônico ou gráfico, reserva-lhes o nome de heteronímia.

Outra questão em foco é tomar a homonímia sob as perspectivas diacrônica ou sincrônica. Os estudos diacrônicos anunciam que uma palavra homonímica especialmente os homônimos perfeitos (mesmo som, mesma grafia) - é a presença em uma única marca significante de duas formas que, historicamente, por fatores fonéticos, se acolheram na similitude. Os dicionários reservam duas entradas diferentes para elas.

Tomando por base o dicionário brasileiro Houaiss (2001), as palavras: manga $^{1}$ - do lat. "manica" (parte do vestuário onde se enfia o braço), manga ${ }^{2}$ - do lat. "manus" (exército, hoste, grupo, ajuntamento, bando, turma) e manga ${ }^{3}$ - do malaiala "mangâ" ( o fruto da mangueira) seriam palavras homonímicas.

O semanticista Palmer (1979) anuncia que não é suficiente consultar um bom dicionário para saber se uma palavra é homonímica ou polissêmica, pois os dicionaristas muitas vezes se deixam guiar por critérios na maioria das vezes arbitrários e até mesmo "subjetivos". Consoante o semanticista, o estado da língua nem sempre revela sua evolução.

Na língua francesa, encontramos no dicionário Larousse (2009) a palavra "bas" registrada como homonímica. Os dois sentidos (dentre outros apresentados), considerados diferentes, "de pouca altura/pouco valor" e "vestimenta que cobre o pé", parecem estabelecer uma relação metafórica. Uma vestimenta, cuja função seria cobrir o pé, sendo o pé a parte mais baixa do corpo, poderia ser tomada como uma "vestimenta de pouca altura". Se essas relações metafóricas terrificam o fenômeno da homonímia, deixam-nos à deriva no momento de decidir se a palavra é homonímica ou não. A dificuldade de estabelecer limites para os sentidos das palavras não é uma tarefa fácil, tanto mais quando o jogo interno da língua nos coloca no ponto em que é possível que qualquer palavra de uma língua venha encontrar-se mediante uma ocorrência 
homonímica. Ou até mesmo uma letra, como o "F", nome da família do manuscrito que estamos analisando.

Percorrer, ainda que minimamente e sem os aprofundamentos necessários, a discussão dos linguistas sobre a homonímia é significativo para compreendermos como a posição mediante os fatos da língua imprime discursos aparentemente díspares. Mattoso Câmara (1986) é sensível à dificuldade no traçado dos limites que separam o fenômeno da homonímia e o da polissemia. Dada a incerteza dos limites dos sentidos das palavras, credita que a homonímia responde por "uma deficiência do princípio geral da distinção fonológica como base da distinção formal" (CÂMARA, 1964, p.184); já André Martinet (1995) e Ullman (1977) consideram a homonímia e, do mesmo modo, a polissemia, como resultantes do princípio da economia linguística. Creditar a deficiência ou a eficiência (essa operacionalizada pelo princípio da economia) como responsáveis pela homonímica parece apagar a natureza dos fatos. O fenômeno da homonímia só pode ser pensado a partir da relação sujeito-língua.

A primeira emergência do termo "fim" no fluxo do dizer destas alunas, e seu movimento para outra posição na cadeia sintagmática, indica sua distância do grupo de palavras homonímicas já cristalizadas; assim como a impossibilidade de se assumir duas entradas diferentes em um dicionário. É isto que diz a "ocorrência homonímica", a impossibilidade de cristalizar toda a língua em um dicionário ou em uma gramática. Se "tudo" na língua pode padecer dessa "ocorrência homonímica", nem tudo na língua pode ser guardado no espaço do repetível.

\section{A HOMONÍMIA NA'LÍNGUA E A CRIAÇÃO}

São as leis saussurianas que subjazem ao fato de que "as palavras e as letras adquirem uma autonomia até então desconhecida", como diz Willemart ao também acrescentar que o "escritor se torna scriptor, isto é, se coloca a serviço da língua". A criação ressalta de uma espécie de alteridade outorgada pela possibilidade de ocorrência de movências imprevisíveis. É essa alteridade que está na gênese da "ocorrência homonímica".

Nessa linha de pensamento, já não seria importante indagar se "fim" é uma palavra com dois sentidos ou se teríamos "fim" e "fim", duas palavras cada uma com seu sentido próprio. Do mesmo modo, como acontece na literatura, também seria desnecessário traçar limites entre a homonímia e a polissemia. Esse posicionamento do linguista frente à língua é prescindível para descrever seu funcionamento, as categorias que a compõem, mas, por outro lado, apaga a dimensão movente da língua, que ameaça qualquer classificação.

Consoante Milner, a língua porta esta dimensão do não-todo, do equívoco, rubrica que responde pelo não idêntico, por "tudo aquilo que promove homofonia, homossemia, homografia, tudo o que suporta o duplo sentido e o dizer em meias palavras, incessante tecido de nossas conversações" (1987, p.12-13). A língua não deixa de ser constantemente desestratificada por esta dimensão, pois, enquanto todo, a língua suporta o não todo, o "real da alíngua" que é "em toda língua o registro que a consagra ao equívoco" (MILNER, 1987, p.9).

A "ocorrência homonímia" opera desde o nível fonético até o sintático, opera cortes inesperados, desestabiliza os estratos, paradigmas e categorias linguísticas, colocando a língua em excesso (MILNER, 1987). A radical homonímia manifesta um dos pontos em que é possível "iluminar a relação da língua à alíngua" (1987, p.16). O 
real da "alíngua" ${ }^{1 "}$ se manifesta quando o idêntico retorna sobre a forma do não idêntico, afetando o espaço do repetível próprio à língua (GADET; PÊCHEUX, 1981). É o próprio funcionamento paradigmático e sintagmático constitutivo da língua que subverte as instâncias estabilizadas e cristalizadas. Disto segue que Milner (1983, p.40) defende que "nenhum ser falante pode se vangloriar de ter o controle dos ecos múltiplos de seu dizer".

No registro do texto dialogal do processo de escritura da história inventada "A família F atrapalhada", as expressões - "rindo", "com voz muito baixa", "falando alto", "você me deu uma boa ideia" - registradas pela filmadora e anotadas pelo pesquisador marcam a posição de Nara e Isabel frente às possibilidades imprevisíveis de deslocar uma palavra de uma posição para outra. Essas expressões simbolizam o reconhecimento de "pontos de encontros inesperados onde se juntam o acaso, as probabilidades, as ideias iniciais e as formas novas" (WILLEMART, 1999, p.91).

Cada uma das meninas lida com a nova possibilidade do significante de uma maneira diferente, o que se configura através das oscilações na voz, no riso... na euforia (“- Calma!", linha 9) .

\section{A REPETIÇÃO DE OUTRA ORDEM}

O diálogo entre Nara e Isabel se alimenta do estável e da repetição do equívoco, de modo que é a intensidade do jogo com as palavras que dá prosseguimento à história:

ISABEL: - E a mãe chamava fima e o pai chamava fimo (rindo).

NARA: - Ah! Não, fumo o pai chamava... e a mãe chamava fina... (rindo).

Os nomes próprios "fima" e "fimo" são imediatamente descartados, mesmo que estabeleçam relações na série de nomes próprios que constituem uma família. Todos começam com a letra ' $F$ ' marcando uma afiliação. Todavia, não dizem nada, não provocam o riso, poderíamos dizer. Já as palavras "fim", "fina" e "fumo" ressaltam o dessemelhante que espreita qualquer palavra da língua, ativado pelas escutas poéticas, pela capacidade de haver deslocamentos na relação significante/significado no interior do signo linguístico.

Pode-se considerar que haja, aí, a manifestação de um padrão específico: os nomes próprios se iniciam com a mesma letra; os nomes próprios são palavras que entraram na história por um movimento de ressignificação, de sorte que "fina", cujo significado "pessoa magra", e "fumo", "material orgânico que compõe o cigarro", ganham novas possibilidades de uso: referenciar-se como nomes próprios.

Observa-se que o texto coloca em cena as possibilidades da língua e de seu funcionamento. Na língua portuguesa, palavras como "fim", "fina" e "fumo" apresentam sentidos diferentes. Como vimos, "Fim" tem o sentido estabilizado de término, conclusão; "Fina", ainda segundo Houaiss (2001), significa "delgado, espesso, estreita..." e "Fumo", pode ser entendido como "tabaco, espécie de cigarro etc.".

Isabel, com voz baixa, anuncia o imprevisível; Nara reconhece a "boa ideia". As meninas sorriem, falam alto, se agitam; o reconhecimento da duplicidade dos sentidos instaurado no significante promove no texto a quebra de relações estabilizadas, de modo que Nara e Isabel deixam de lado nomes próprios (Fima/Fimo) que não

${ }^{1}$ A palavra "alíngua" é tradução de lalangue, termo forjado por Jacques Lacan para defender que o "inconsciente" fala através da estrutura simbólica da lalangue. 
promovem equívocos. A possibilidade de "ocorrência homonímica" interfere na forma como os outros nomes próprios se materializam na versão escrita final da produção do manuscrito. Assim, na abertura e no fechamento das cadeias em destaque, "fim, fina e fumo" assumem lugar de nomes próprios.

A ocorrência homonímica está atrelada, nas palavras de Calil e Lima (2013), aos processos metafóricos e metonímicos e enlaçada com as noções de "escuta" e "reconhecimento". A escuta, sempre singular e imprevisível, manifesta a jocosidade na construção da história, como pode ser destacado no manuscrito "A família $\mathrm{F}$ atrapalhada", transcrita aqui.

Figura 1 - Manuscrito “A família F atrapalhada” e sua transcrição normativa.

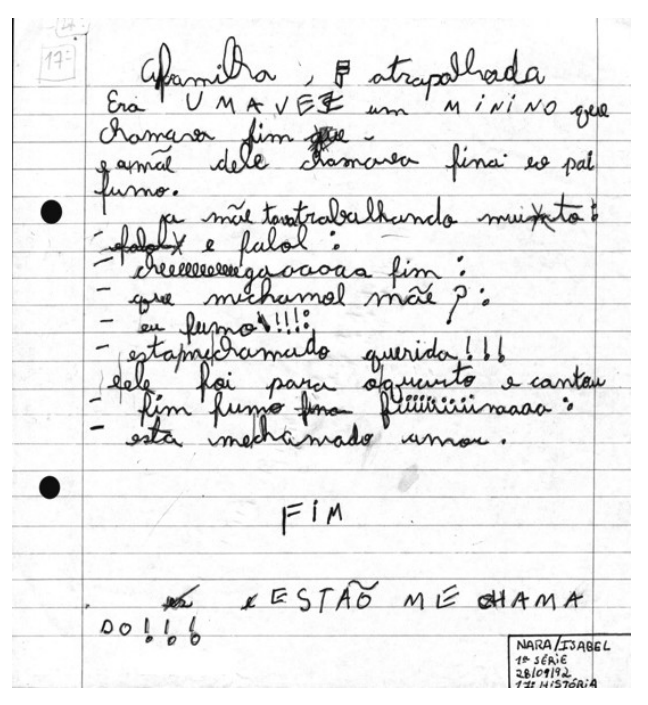

A família $\mathrm{F}$ atrapalhada

Era uma vez um menino que chamava fim

e a mãe dele chamava fina e o pai fumo.

a mãe tava trabalhando muito:

e falou:

- cheeeeeeeeeegaaaaaa fim:

- que me chamou mãe?:

- eu fumo!!!!:

está me chamando querida!!!

e ele foi para o quarto e cantou

- fim fumo fina fiiiiiiiiiiinaaaa:

- está me chamando amor

FIM

\section{ESTÃO ME CHAMANDO!!!}

O texto traz no título o adjetivo "atrapalhada", alçado à condição de sobrenome, que simboliza, também, a confusão e os mal-entendidos nos diálogos estabelecidos entre as personagens da história inventada. Os movimentos imprevisíveis presentes nos diálogos de Nara e Isabel é o fato estruturante do próprio texto.

Observemos que a fala direta da personagem-mãe "cheeeeeeeeeega fim" estabelece uma conexão metonímica com a frase anterior "a mãe tava trabalhando muito e falou", de modo que reflete a queixa da mãe mediante trabalho exaustivo (CALIL, 2004).

Expressões dessa natureza são comuns em situações reais, frequentemente ouvidas e ditas por crianças e adultos, o que não promove estranhamento na continuidade temática da história. Todavia, a estrutura "cheeeeeeeeeega fim" é eivada de significados, como sugere a fala da personagem-filho "que me chamou mãe?" 1. a expressão pode indicar um ato de chamamento - em algumas regiões do Brasil - "venha cá, fim, eu estou chamando"; 2. a expressão pode ser utilizada para chamar a atenção das pessoas, pedindo para que elas parem de fazer algo que não agrada a outrem, daí, "pode parar, fim".

Nesse sentido, podemos reconhecer que as duas interpretações são admissíveis, interligando cadeias metonímicas que ultrapassam uma a outra. A história mantém esse ritmo; cada enunciado reflete pontos de derivas incessantes: 

a) - Cheeeeeeeeeeega fimmmmmmm
- que me chamou mãe
b) - eu fumo
- está me chamando querida
c) - fim, fumo, fiiiiiiiiiiiiiiiiiiiiiiiinaaaa
- está me chamando amor
d) FIM
- estão me chamando

Em cada momento que se denomina um personagem, as expressões (anotação das falas dos personagens) "que me chamou mãe", "está me chamando querida", "está me chamando amor" e "estão me chamando" presentificam um ponto do duplo, de deriva, pois o ato de nomear é também o de "chamamento", "interpelação". A repetição das letras "e" e "i" nas palavras "cheeeeeeeeeega" e "fiiiiiiiiiiinaaaa" simboliza, de modo significativo, os modos como, na oralidade, o chamamento também se realiza através do alongamento sonoro, da reverberação vocálica.

A história não tem fim, e isso acontece pelo fato de que o ato de nomear é, também, o ato de chamar (a atenção dos personagens). Ao nomear o "FIM" da história, os escreventes sedimentam a deriva incessante da história. Marcam, com a expressão "estão me chamando", que a história inventada é estruturada pelo excesso, por uma força que os ultrapassa.

Figura 2 - Extrato do manuscrito "A família F atrapalhada"

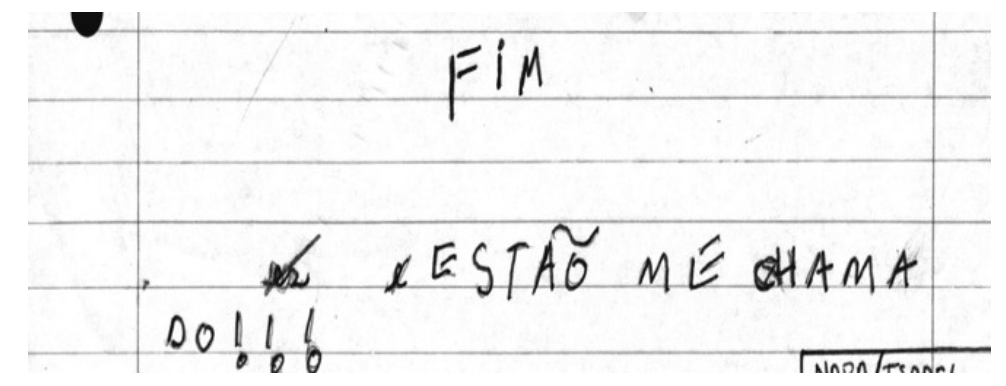

Na história da "A família F atrapalhada", uma frase emenda a outra, mantendo entre elas uma conexão metafórica e metonímica imediata. O jogo de sentido se constitui pelas ocorrências homonímicas dadas através da repetição de estruturas de "nomear" e "responder a um chamamento".

\section{CONSIDERAÇÕES FINAIS}

As meninas Nara e Isabel, apesar de serem escreventes novatas, assumem a posição de scriptor, conforme definiu Willemart. Não somente o manuscrito escolar "A família $\mathrm{F}$ atrapalhada" sugere isso, mas também o diálogo estabelecido durante $\mathrm{o}$ manuscrito em curso. O enunciado final da história, "estão me chamando", sintetiza o jogo destas ocorrências. Chistosamente, as meninas passam de uma cena a outra, amarrando e desamarrando significados para um único significante. Com isso, elas revelam a alteridade do significante e suas possibilidades de produzir efeitos.

O manuscrito escolar, por si, contempla frutíferas discussões. Mas o processo escritural da história, por sua vez, abre ao "nascimento da história", para a relação dos 
alunos com o modo de funcionamento da língua, reconhecendo nele aquilo que pode alimentar o processo criativo, isto é, as possibilidades imprevisíveis e os deslocamentos entre os significados e os significantes.

A lógica preestabelecida que coloca a palavra "fim" como indício de término é descartada por Nara e Isabel, de modo que, presas na forquilha da homonímia, rasuram oralmente, como proposto por Calil (2013), o sentido da palavra "fim". Neste caso, a rasura oral sobre a palavra "fim" (fim da história) desloca o significante para outra posição na cadeia sintagmática e, junto com ele, um sentido inesperado surge.

Como diz Willemart, "toda rasura e todo acréscimo podem ser considerados início de uma nova página e de um novo parágrafo" (WILLEMART, 1999, p.91). Os começos são múltiplos, os pontos de partidas infinitos, o texto novo pode emergir de qualquer acréscimo. A história de Isabel e Nara se sustenta sob um efeito de não acabado, pois a história se redobra no dobro da homonímia. A homonímia sustenta o efeito de inacabado e, como continua Willemart, "o inacabado é fundamental, as possibilidades surgem a qualquer instante como sob a varinha mágica de uma feiticeira" (1999, p.91).

Defendemos a diferença entre homonímia, como forma estabilizada na língua, cujos termos recebem entradas diferentes nos dicionários, da ocorrência homonímica. Dar estatuto a esta ocorrência permite considerar que a língua, toda ela, é um ponto de deriva incessante, especialmente quando se trata de processos de nomeação. Qualquer palavra da língua pode ocupar a posição de nome próprio.

Considerar a "ocorrência homonímica" como um dos fenômenos responsável pela criação textual e ter como objeto de análise a filmagem de situações de escritura colaborativa pode trazer um significativo ganho para os estudos sobre a escritura e autoria de alunos recém alfabetizados. A troca intersubjetiva na escritura de um único texto, em contexto escolar, parece contribuir para os embates linguísticos e discursivos provocados pelo ato enunciativo de cada escrevente, e favorecendo a constituição de uma posição de scriptor que possa reconhecer a dimensão imprevisível da língua e do sentido, ainda que esteja submetido a uma prática didática que trata a língua de modo homogeneizado e normativo.

\section{REFERÊNCIAS BIBLIOGRÁFICAS}

AUTHIER-REVUZ, Jacqueline. Palavras Incertas: as não coincidências do dizer. Campinas: São Paulo: Editora da Unicamp, 1998.

BIASI, Pierre-Marc de. Génétique des textes. Paris: CNRS Editions, 2011.

CALIL, Eduardo. Autoria: a criança e a escrita de histórias inventadas. Londrina/PR: EdueL, 2004.

CALIL, Eduardo. Escutar o invisível : escritura e poesia na sala de aula. Campinas: Editora Unesp/Funart, 2008.

CALIL, Eduardo. « Dialogisme, hasard et rature orale Analyse génétique de la création d un texte par des élèves de 6 ans. In: Eduardo Calil; Catherine Boré. (Org.). L'école, l'écriture et la création: Études franco-brésiliennes. Louvain-la-neuve: L'HarmattanAcademia, pp. 157-188, 2013. 
CALIL, Eduardo ; LIMA, Maria Hozanete Alves de. « Les noms propres dans des histoires inventées : effets d un enchaînement ». In: Eduardo Calil; Catherine Boré. (Org.). L école, l écritutre et la création : Études franco-brésiliennes. Louvain-la-neuve: L Harmattan-Academia, pp. 203-223, 2013.

CÂMARA Jr., J. Mattoso. Dicionário de Filologia e Gramática. Rio de Janeiro/São Paulo: J. Ozon Editor, 1964.

CÂMARA Jr., J. Mattoso. Estrutura da Língua Portuguesa. Petrópolis/RJ: Vozes, 1986.

DUBOIS, Jean et al.. Dicionário de Lingüística. São Paulo: Cultrix, 1993.

FABRE, Claudine. "Variantes de réécriture, citations, discours rapportes a l'école élémentaire" Cahiers d'Acquisition et de pathologie du langage: Réécriture \& interactive en situation scolaire, fascicule 9. Centre National de la Recherche Scientifique Université René Descartes. Paris V, pp. 9-19, 1992.

FABRE, Claudine. Les brouillons d'écoliers ou l'entrée dans l'écriture. Grenoble: Ceditel / L'Atelier du Texte, 1990.

FABRE, Claudine, Das variantes do rascunho ao curso preparatório. Debates em Educação, v. 5, pp. 22-65, 2013.

FELIPETO, Cristina. Rasura e equívoco no processo de escritura em sala de aula. Londrina: Eduel, 2008.

GADET, Françoise ; PÊCHEUX, Michel. La langue introuvable. Paris: François Maspero, 1981.

GRÉSILLON, Almuth. Eléments de critique génétique: lire les manuscrits modernes. Paris: PUF, 1994.

HOUAISS, Antônio. Dicionário Eletrônico da Língua Portuguesa. Rio de Janeiro: Editora Objetiva; Instituto Antônio Houaiss, 2001.

JOTA, Zélio dos Santos. Dicionário de Linguística. Rio de Janeiro: Presença; Brasília: INL, 1981 .

LAROUSSE. Dictionnaire des Homonymes. France/Paris: Éditions Larousse; Petit Robert. France: 2009.

LYONS, John. Linguagem e Linguística: uma introdução. Rio de Janeiro: Livros Técnicos e Científicos Editora S\&A, 1987.

MARTINET, André. Função e Dinâmica das Línguas. Coimbra, Almedina, 1995. 
MILNER, Jean-Claude. Les noms indistincts. Paris: Seuil, 1983.

MILNER, Jean-Claude. O Amor da Língua. Porto Alegre: Artes Médicas, 1987.

PALMER, F. R. A Semântica. São Paulo: Edições 70, 1979.

SAUSSURE, Ferdinand de. Curso de Linguística Geral. São Paulo: Cultrix, 1999.

ULLMAN, Stephen. Uma introdução à Ciência do Significado. Coimbra: Fund. Gulbenkian, 1977.

WILLEMART, Philippe. Bastidores da criação literária. São Paulo: Iluminuras, 1999.

Recebido em: 02 de janeiro de 2014.

Aceito em: 17 de fevereiro de 2014. 